\title{
Evaluation of Role of Concurrent Chemotherapy and Brachytherapy in Locally Advanced Cervical Cancer Patients
}

\section{Sanjay Singh Chandel ${ }^{1 *}$ and Rajesh Kumar Jain ${ }^{2}$}

${ }^{1}$ Department of Radiation Oncology, GR Medical College, Gwalior, Madhya Pradesh, India

${ }^{2}$ Department of Radiation Oncology, NSCB Medical College, Jabalpur, India

\begin{abstract}
Aim: Carcinoma of Uterine cervix is the commonest cancer affecting females in developing countries Concurrent chemoradiation has remained the sole definitive treatment available in the advanced stages. The study was planned to take the advantage of radiosensitisation accruing due to chemotherapy at the time of brachytherapy, when approximately forty percent of total tumor dose is applied.
\end{abstract}

Materials and methods: 64 patients were enrolled who had locally advanced uterine cervix carcinoma (FIGO stage IIB to IVA) from July 2011 to May 2013 for concurrent chemotherapy and intracavitory brachytherapy after completion of concurrent chemotherapy and external beam radiotherapy followed by 3 insertion of brachytherapy separated by a week by Flexitron brachytherapy unit to point A, for each application was 6 Gy by HDR. Cisplatin was given $\left(35 \mathrm{mg} / \mathrm{m}^{2}\right)$ one day before brachytherapy in each application.

Results: At medium follow-up of 19 months (range 8 to 30 months) clinical complete response rate was found to be $89 \%$ at 3 months of follow up. Acute side effect as nausea and vomiting grade I and II were recorded as $55 \%$ and $28 \%$ respectively, no renal dysfunction and no thrombocytopenia were encountered. No patients had grade IV or life threatening toxicity. Overall survival and disease free survival after 30 months of follow up is $88 \%$ and $75 \%$ respectively.

Conclusion: Use of concurrent chemotherapy with brachytherapy is effective and feasible with acceptable toxicity for locally advanced carcinoma of the uterine Cervix.

Keywords: Cervical carcinoma; Brachytherapy; Concurrent chemotherapy

\section{Introduction}

Carcinoma of uterine cervix is the commonest cancer of females in developing countries [1]. Concurrent chemoradiation has remained the standard treatment available for locally advanced cases [2]. Cervical carcinoma in early stages is quite radioresponsive, however, in locally advanced stages, the long-term outlook has consistently remained grim on account of central or peripheral failures. Treatment failure outside the radiation field is well encountered. However, the persistent/ recurrent pelvic disease remains a significant obstacle in curative intent and prolonged survival. According to recent published literature approximately half of locally advanced disease fails in treated pelvic area $[2,3]$. This is attributable to presence of bulk of the primary lesion with its attendant increase in hypoxic cells, poor geometry, impaired blood supply and increase in growth fraction thereby resulting in poor radiation response.

Standard treatment regimen for such cases has remained external beam radiation with concurrent chemotherapy followed by brachytherapy wherever possible [4]. Cure is interlinked with radiation dose escalation however; such ingredients to improve local control by increasing radiation dose are hampered by the limited tolerance of surrounding critical organs. Attempts have been made to improve the local control and survival in the advanced stages of the disease by combination of radio-sensitizer like cisplatin with external beam radiation. Several authors have claimed overall improvement of disease-free survival as compared to treatment with radiation alone [5-9].

This study aims to evaluate the efficacy, feasibility and toxicity of concurrent chemotherapy and brachytherapy for locally advanced cervical carcinoma (LACC). It has been found that this modality in LACC has not been systematically evaluated in prospective set up. The study aims to quantify objectively the potential to improve the loco regional control, disease free survivals, normal tissue toxicities (acute \& late), overall survivals and possibility of recurrences and distant metastasis rates.

\section{Material and Methods}

Sixty four patients who had advanced uterine cervical carcinoma and treated with concurrent chemotherapy and external beam radiation were enrolled from July 2011 to May 2013 for concurrent chemotherapy and brachytherapy. Patient's details are charted in Table 1.

The patients with advanced cervical cancers (stage IIB- IVA) who received whole pelvis external beam radiotherapy with $6 \mathrm{MV}$ photons on Siemens primus linear accelerator to a tumor dose of $50 \mathrm{~Gy} / 25 \# / 5$ weeks with concurrent Cisplatin $35 \mathrm{mg} / \mathrm{m}^{2}$ weekly. After one week interval, intracavitory brachytherapy was administered. All patients were planned on Multi-slice CT scanner and complete evaluation of

*Corresponding author: Chandel SS, Assistant Professor, Department of Radiation Oncology, GR Medical College, Katora Tal Road, Lashkar, Gwalior, Madhya Pradesh 474009, India, Tel: 7389350645; E-mail: drrajeshonco@gmail.com

Received November 19, 2015; Accepted January 21, 2016; Published January 23, 2016

Citation: Chandel SS, Jain RK (2016) Evaluation of Role of Concurren Chemotherapy and Brachytherapy in Locally Advanced Cervical Cancer Patients. J Cancer Sci Ther 8: 010-014. doi:10.4172/1948-5956.1000380

Copyright: (c) 2016 Chandel SS, et al. This is an open-access article distributed under the terms of the Creative Commons Attribution License, which permits unrestricted use, distribution, and reproduction in any medium, provided the original author and source are credited. 


\begin{tabular}{|c|c|}
\hline Median age (year & \\
\hline Histologic type & \\
\hline Squamous & 59 (92.2\%) \\
\hline Adenosquamous & $05(07.8 \%)$ \\
\hline Adenomatous & $00(00.0 \%)$ \\
\hline FIGO stage & \\
\hline IIB & $08(12.5 \%)$ \\
\hline IIIA & $11(17.2 \%)$ \\
\hline IIIB & $36(56.2 \%)$ \\
\hline IVA & $09(14 \%)$ \\
\hline Karnofsky' perfo & \\
\hline 70 & $14(21.8 \%)$ \\
\hline 80 & $20(31.2 \%)$ \\
\hline$>90$ & $30(46.8 \%)$ \\
\hline
\end{tabular}

Table 1: Pretreatment patient characteristics $(n=64)$

the local disease and its correlation with critical structure were noted. 3DCRT plan were generated using DICOM for data transfer from CTSIM to TPS for eliminate personal errors. Dosage to critical structure, GTV and Lymphatic's were recorded.

The selection of the patients had stringent selection and rejection criteria. All patients who received definitive external radiotherapy and chemotherapy were included. Written and informed consent of the entire patient included in the study were taken. Pathology of uterine cervix tumor other than squamous cell carcinoma (SCC) and adenosquamous carcinoma were not included, Details in Table 1. The patients who could not have standard protocol are not included for the study. All patients in this study treated with same radiation and chemotherapy dose irrespective of stages of patients.

The selected patient underwent 3 \# of brachytherapy by Flexitron brachytherapy unit and the dose to point $\mathrm{A}$ for each application was 6 Gy by high dose rate. Chemotherapy consisting of Cisplatin was infused $\left(35 \mathrm{mg} / \mathrm{m}^{2}\right)$ one day before intracavitary irradiation in each application. Each patient was planned on CT-SIM and ICRU -38 dosimetric methods was utilized to evaluate the dosage to reference volume and various pelvic structures.

Intracavitary brachytherapy protocol included evaluation and application under general anesthesia. The intrauterine tandem with appropriate size and angle was inserted in the uterus after dilatation of uterine cervix and two colpostats were placed in the vaginal vault with appropriate packing by Fletcher system, all patients received same radiation dose no vaginal cylinder were used because we excluded patints with lower third of vaginal involved and post-operative case where cylinder was appropriate option. CT simulation of the pelvis done and treatment planning with flexitron software were performed. Point A, bladder, rectum, and parametrial points according to the ICRU-38 recommendations were determined. Total dose of $18 \mathrm{~Gy}$ to point A was delivered in three fractions separated by a week with dose of 6 Gy per fraction with high dose rate. The maximal dose was limited to low dose rate equivalent 70 Gy to the rectum and 75 Gy to the bladder (Figure 1). Partial volumes of the rectum and bladder falling in reference volume were recorded to objectively access the toxicity.

\section{Chemotherapy protocol}

Complete hematological and biochemical evaluation was done and Cisplatin was prescribed intravenously at doses of $35 \mathrm{mg} / \mathrm{m}^{2}$ given in normal saline during 2 hour infusion one day before each insertion. Preventive medication for nausea and vomiting was routinely administered.

\section{Evaluation of follow-up}

Before each course of CT patients were evaluated and during RT they were seen weekly by Radiation oncologist for normal tissue reaction and tumor response. Routine investigations were performed and if required supportive management was given. As per RTOG criteria adverse reaction was documented. During CT all patient were admitted in ward. Patients were examined after completion of RT and then at 6 weeks followed by 3 monthly bases up to two years than six monthly. Blood count, $\mathrm{x}$-ray chest, USG abdomen. Patients belong to rural area were also motivated to come for regular follow up.

\section{Response}

After completion of treatment, all patients were evaluated for response and acute toxicity. Response was evaluated three months after the end of radiotherapy by means of clinical examination and computed scan of pelvis. Complete regression (CR) was defined as disappearance of the disease according to both clinical and radiological examination. Partial regression (PR) was defined as tumor size regression more than $50 \%$. A regression of less than $50 \%$ or stable disease (SD) was defined as no change (NC). Acute hematological toxicity was monitored weekly during treatment through serum examination and blood cell counts. Patient symptoms like diarrhoea, vomiting, dysuria were reported. Toxicity was scored according to WHO criteria.

\section{Statistical methods}

Patient characteristics, safety profile of the concurrent modality treatment administration, and response rates were characterized by descriptive methods. Locoregional relapse free survival (LRFS), Disease free survival (DFS) and overall survival (OS) curves were calculated according to the Kaplan- Meier method. For LRFS all local and /or regional recurrences and deaths due to disease were taken as events, for DFS all the deaths because of disease were taken as events, while
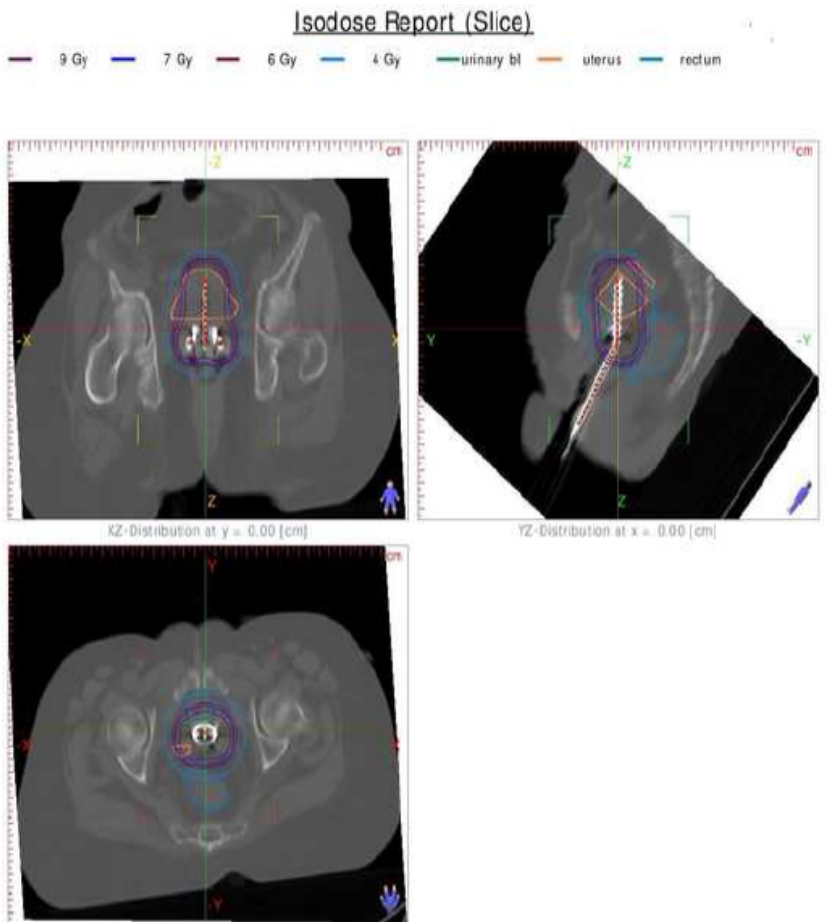

Figure 1: Isodose report (Slice). 
for overall survival (OS) all deaths regardless of any cause were taken as events.

\section{Results}

Initial results of this study were found to be very encouraging. Follow up range was 8 to 30 months, median follow up 19 months. The clinical complete response rate is $89 \%$ at 3 months of follow up. Overall survival and disease free survival after 30 months of follow up is $88 \%$ and $75 \%$ respectively (Table 2). Stage wise response and pattern of failure were included in Table 3.

Acute side effect as nausea and vomiting grade I and II is $55 \%$ and $28 \%$ respectively, no patients had reported renal dysfunction and thrombocytopenia. Grade II, III leucopenia is $11 \%$ and $6 \%$ respectively. All acute side effects were well managed with ondensetron and filgrastim support. No patient had grade 4 or life threatening toxicity (Table 4). Late toxicities in 30 months of follow-up only one patient reported rectal fistula and two patients reported uncontrolled rectal bleeding which requires laser coagulation, others were well managed with symptomatic treatment (Table 5).

\section{Discussions}

Radical radiotherapy (External radiotherapy+brachytherapy) is standard treatment option available for locally advanced cervical carcinoma with use of concurrent chemotherapy during external radiotherapy. The dose of radiation depend upon stage of disease, parametrial involvement, lymph node involvement, institutional protocol etc. in early cervical carcinoma more dose was given with brachytherapy while in advanced cervical carcinoma more dose was given with external radiotherapy. According to American brachytherapy society total dose (external+brachy) in early cases was 80-85 Gy and in advanced cases 85-90 Gy of LDR equivalents. Many authors reported similar results with lower radiation dose with similar effects and less complications rates [10]. In our study we delivered 50 Gy by external and 18 Gy (6@3 fractions) by HDR brachytherapy.

Meataanalysis of 5 randomized trial report published in February 1999 shows that concurrent chemoradiation with cisplatin a dose of $40 \mathrm{mg} / \mathrm{m}^{2}$ on weekly basis is standard of care in LACC. In our study dose of cisplatin $35 \mathrm{mg} / \mathrm{m}^{2}$ was used on weekly basis as radiosensitizer it is little lower side because review of this reports also shows that only $67 \%$ of patients completed 6 cycle of plane chemotherapy due to acute toxicity of chemotherapy [11]. Punushapai et al. [12]. found in there study that concurrent chemoradiotherapy with weekly cisplatin $40 \mathrm{mg} /$ $\mathrm{m}^{2}$ in locally advanced cervical cancer gives good treatment outcomes. When reducing the cisplatin dose to $20 \mathrm{mg} / \mathrm{m}^{2}$, treatment responses were still comparable to the standard, but acute toxicity could be reduced. The $40 \mathrm{mg} / \mathrm{m}^{2}$ group showed unplanned interruptions in $13 / 70(18.6 \%)$, which was significantly different from the $5 / 70(7.1 \%)$ in the $20 \mathrm{mg} / \mathrm{m}^{2}$ group $(\mathrm{p}=0.02)$, resulting in prolonged treatment time $(\mathrm{p}=0.026)$. Complete responses were found in 69/70 (98.6\%) and 68/70 (97.1\%), respectively, with no significant difference. Hematological and gastrointestinal toxicities were most frequently observed. Acute toxicities in the first group was significantly higher when compared to the second group $(\mathrm{p}<0.05)$ as follows; grade $1-2$ leukopenia $(14.8 \%$ vs. $6.4 \%)$, grade $1-2$ neutropenia ( $9.3 \%$ vs. $2.6 \%)$, grade $2 \mathrm{~N} / \mathrm{V}(3.8 \%$ vs.

\begin{tabular}{|c|c|c|c|c|c|c|c|}
\hline $\begin{array}{c}\text { Complete } \\
\text { response }\end{array}$ & $\mathbf{3}$ months & $\mathbf{6}$ months & $\mathbf{9}$ months & $\mathbf{1 2}$ months & $\mathbf{1 8}$ months & $\mathbf{2 4}$ months & $\mathbf{3 0}$ months \\
\hline $\begin{array}{c}\text { Partial Response/ } \\
\text { Progression }\end{array}$ & $\mathrm{PR}=11 \%$ & $\begin{array}{c}\mathrm{CR}=84.3 \% \\
\mathrm{PR}=9 \%\end{array}$ & $\mathrm{CR}=82.8 \%$ & $\mathrm{CR}=79.6 \%$ & $\mathrm{CR}=78 \%$ & $\mathrm{CR}=76 \%$ & $\mathrm{CR}=75 \%$ \\
\hline
\end{tabular}

Table 2: Response rate of 30 months of follow-up.

\begin{tabular}{|c|c|c|c|c|c|}
\hline & Death & Metastasis & Local response & Missing & Complete response \\
\hline IIB & 01 & 00 & 00 & 01 & 06 \\
\hline IIIA & 00 & 00 & 00 & 00 & 11 \\
\hline IIIB & 01 & 01 & 05 & 02 & 01 \\
\hline IVA & 02 & 01 & 01 & 01 \\
\hline
\end{tabular}

Table 3: The number of patients in each stage of cervical cancer and the results in the 30 months follow-up.

\begin{tabular}{|c|c|c|c|c|}
\hline & Grade 0 & Grade 1 & Grade 2 & Grade 3 \\
\hline Leukopenia & $55 \%$ & $26 \%$ & $11 \%$ & $06 \%$ \\
\hline Thrombocytopenia & $100 \%$ & $00 \%$ & $00 \%$ & $00 \%$ \\
\hline Anemia & $62 \%$ & $21 \%$ & $13 \%$ & $04 \%$ \\
\hline Nausea, vomiting & $17 \%$ & $55 \%$ & $28 \%$ & $00 \%$ \\
\hline Diarrhea & $45 \%$ & $36 \%$ & $15 \%$ & $04 \%$ \\
\hline
\end{tabular}

Table 4: Acute toxicities as per ECOG criteria $(n=64)$.

\begin{tabular}{|c|c|c|c|c|c|c|}
\hline & 6 months & 9 months & 12 months & 16 months & 20 months & 30 months \\
\hline Proctitis & $\begin{array}{c}\mathrm{Gl}=23 \% \\
\mathrm{Gl}=16.6 \%\end{array}$ & $\begin{array}{l}\mathrm{GI}=21 \% \\
\mathrm{GII}=13 \%\end{array}$ & $\begin{array}{c}\mathrm{Gl}=18 \% \\
\mathrm{G} I=11 \% \\
\mathrm{GIII}=3.1 \%\end{array}$ & $\begin{array}{c}\mathrm{Gl}=13 \% \\
\mathrm{G} \|=9 \% \\
\mathrm{GIII}=3.1 \%\end{array}$ & $\mathrm{G} I I=4.6 \%$ & $\mathrm{GII}=1.5 \%$ \\
\hline Abdominal Pain & $\begin{array}{l}\mathrm{Gl}=18 \% \\
\mathrm{G} \|=11 \%\end{array}$ & $\begin{array}{c}\mathrm{Gl}=18 \% \\
\mathrm{G} \|=4\end{array}$ & $\mathrm{GI}=5 \%$ & $\mathrm{GRI}=8 \%$ & $\mathrm{GI}=8 \%$ & 00 \\
\hline Cystitis & $\begin{array}{l}\mathrm{GI}=18 \% \\
\mathrm{G} \|=6 \%\end{array}$ & $\begin{array}{l}\mathrm{GI}=13 \% \\
\mathrm{GII}=14 \%\end{array}$ & $\begin{array}{l}\mathrm{Gl}=6 \% \\
\mathrm{GII}=9 \%\end{array}$ & $\begin{array}{l}\mathrm{Gl}=8 \% \\
\mathrm{Gl} 9 \%\end{array}$ & $\mathrm{GI}=6 \%$ & $\mathrm{GI}=6 \%$ \\
\hline Rectal Fistula & $1.5 \%$ & 00 & 00 & 00 & 00 & 00 \\
\hline
\end{tabular}

Table 5: The late effects (Grade of toxicity) on 30 months of follow-up. 
$1 \%)$, grade 2 diarrhea ( $2.4 \%$ vs. $0.7 \%$ ), and grade 1 sensory neuropathy ( $4.5 \%$ vs. $1.2 \%)$. No treatment related deaths were encountered.

In this study treated 64 patients with stage locally advanced cervical cancers with concurrent Cisplatin and brachytherapy Complete response rate was $88 \%$, and $75 \%$ of the patients were disease free in 30 months follow-up. Acute effects including grade II, III leukopaenia $11 \% \& 6 \%$ respectively and late effects like rectal toxicity grade II, III $2.5 \%$ and $5 \%$ respectively.

Uterine cervical carcinoma is the most common gynecologic cancer in rural India which accounts about $34.4 \%$ of cancers in rural Indian women [13]. External radiotherapy and intracavitary brachytherapy are the standard treatment modalities in advanced-stages cervical carcinomas. In recent years, concurrent chemotherapy with external radiotherapy has improved the treatment outcome in advanced uterine cervical cancers and known as the standard choice of care. Cisplatin is considered the most effective single agent as systemic therapy in eradicating micro metastasis and moreover as a radiosensitizer in uterine cervical carcinoma [14,15]. Cisplatin when simultaneously administered with radiotherapy, have radio sensitivity effects by inhibition of DNA synthesis, inhibition of transcription elongation by DNA inter strand cross-links, inhibition of repair of radiation induced DNA damage and increase the sensitivity of hypoxic cells and cell death [16-19]. About forty percent of total tumor dose is delivered in brachytherapy in uterine cervix and parametriums, and the minimum dose to the rectum and bladder can be achieved by accurate treatment planning. It is logical concept to expect that the best time to apply chemotherapy during the course of radiotherapy will be during the brachytherapy insertions. There are two reasons for this assumption, the dose of radiation applied during one brachytherapy insertion is much higher than external radiation, due to that difference we can expect that the effects of the combination of brachytherapy and chemotherapy are substantially greater than either of both, and the second reason is that the dose rate of brachytherapy is decreasing by inverse-square law and thus potentially results in less toxicity to surrounding normal tissues. There are limited data on concurrent use of chemotherapy and intracavitary brachytherapy in uterine cervical carcinoma. In a phase I, II trial; Kuske et al. [20] used 5FU+cisplatin concurrent with radiotherapy in the first week of treatment and brachytherapy in 23 patients with advanced or recurrent cervical carcinomas and stage II and III uterine cancers. In another study conducted by Stumpf et al. [21], fifty seven cases with cervical cancer were treated with concurrent $5 \mathrm{FU}$ and brachytherapy. The results of both studies showed that concurrent chemotherapy and brachytherapy had better outcome compare to brachytherapy alone. Eduard et al. [22] forty-four patients were assigned to receive external radiotherapy 50 Gy in 25 fractions then all patients received both courses of concomitant chemo brachytherapy and at least 1 cycle of consolidation chemotherapy. The average duration of radiation was 45.1 days. The clinical complete response rate was $100 \%$. Grade III and IV leukopenia occurred in $25 \%$ and $11 \%$ of the cycles, respectively. After a median follow-up of 34 months (range, 20-54 months), the recurrence-free and the overall survival rates were $84 \%$ and $91 \%$, respectively. Major delayed local complications occurred in 7 cases (16\%). These results indicate that concomitant chemo brachyradiotherapy with ifosfamide and cisplatin is a feasible combination for patients with locally advanced carcinoma of the cervix uteri. Koumantakis et al. in Greece [23] treated 36 cases with stage IIA/B-IIIA cervical cancers with external beam radiotherapy and then concurrent Cisplatin or Carboplatin and brachytherapy. The dose to point A was 85-90 Gy. Radical hysterectomy and pelvic lymphadenectomy was performed if possible. In 31 patients who underwent surgery after radiotherapy, $83 \%$ had pathologic complete response. The most common acute effects were hematological toxicities as grade 3, 4 thrombocytopenia in 2 cases and grade 1, 2 anemia and leucopenia in three patients. Local abdominal pain and grade 1, 2 cystitis were noted in six patients. There was no renal dysfunction. In aforementioned study, the patients had surgery by hysterectomy and lymphadenectomy in addition to radiotherapy. Acute hematological toxicities were less common in our study, but the other acute effects were similar.

Strauss et al. treated 27 patients with stage IIB-IIIB cervical cancers with concurrent Cisplatin and brachytherapy in Germany [24]. Complete response rate was $92.3 \%$, and $80 \%$ of the patients were disease free in 20 months follow-up. Acute effects including grade III hematological toxicities and late effects were seen in $29.6 \%$ and $7.4 \%$ of cases, respectively. These toxicities were more common in comparison with our trial.

In the present study, we assessed the efficacy of concurrent Cisplatin and high dose rate brachytherapy in advanced uterine cervical carcinoma. Compared with Strauss et al. [24]. A complete response and disease free survival were $88 \%$ and $75 \%$ vs., $92.3 \%$ and $80 \%$ respectively. Acute effects like grade III hematological toxicities $29.6 \%$ vs. $6 \%$ and late effects like rectal toxicities $7.4 \%$ vs. $5 \%$ respectively. Acute effects specially hematological and renal toxicities, subjective complaints and response rate were acceptable. Interesting findings of this study are very good local control in advanced local disease patients and low metastasis rates (only 5\%) and no grade IV acute and late effects.

Although evaluation of late rectal and bladder effects, observed in the second and third years were accomplished, because of the short period of follow-up, it seems that sub-acute effects (seen in 7-30 months after therapy) were acceptable. This is a preliminary report and long term follow up will be continued. In conclusion, use of concurrent chemotherapy with brachytherapy is effective and feasible with acceptable toxicity for advanced cancer of the uterine cervix. It is recommended to conduct more clinical trials with more intensive dose of chemotherapy or combination of two or three agents. As per our knowledge no randomized study with concurrent chemotherapy and brachytherapy.

However some drawback was also present in this study: It was not randomized, small sample size, shorter duration of follow up and Cause of death of patient is not known.

\section{References}

1. IARC Scientific publication (1997) Cancer incidence in five continents. Volume VII. IARC Sci Publ: i-xxxiv, 1-1240.

2. Vasishta S, Varghese A, Ragheb A (2007) Patterns of failure in cervica carcinoma and outcome of salvage therapy: a retrospective study. Gulf J Oncolog 1: 43-49.

3. Perez CA, Breaux S, Madoc-Jones H, Bedwinek JM, Camel HM, et al. (1983) Radiation therapy alone in the treatment of carcinoma of uterine cervix. I. Analysis of tumor recurrence. Cancer 51: 1393-1402.

4. Perez CA (1998) Uterine cervix. In: Perez CA, Brady LW (eds) Principles and practice of radiation oncology. (3rdedn), Lippincott- Raven Publishers, Philadelphia.

5. Keys HM, Bundy BN, Stehman FB, Muderspach LI, Chafe WE, et al. (1999) Cisplatin, radiation, and adjuvant hysterectomy compared with radiation and adjuvant hysterectomy for bulky stage IB cervical carcinoma. $\mathrm{N}$ Engl J Med 340: 1154-1161.

6. Whitney CW, Sause W, Bundy BN, Malfetano JH, Hannigan EV, et al. (1999) Randomized comparison of fluorouracil plus cisplatin versus hydroxyurea as an adjunct to radiation therapy in stage IIB-IVA carcinoma of the cervix 
Citation: Chandel SS, Jain RK (2016) Evaluation of Role of Concurrent Chemotherapy and Brachytherapy in Locally Advanced Cervical Cancer Patients. J Cancer Sci Ther 8: 010-014. doi:10.4172/1948-5956.1000380

with negative para-aortic lymph nodes: a Gynecologic Oncology Group and Southwest Oncology Group study. J Clin Oncol 17: 1339-1348

7. Morris M, Eifel PJ, Lu J, Grigsby PW, Levenback C, et al. (1999) Pelvic radiation with concurrent chemotherapy compared with pelvic and para-aortic radiation for high-risk cervical cancer. N Engl J Med 340: 1137-1143.

8. Peters WA, Liu PY, Barrett RJ, Stock RJ, Monk BJ, et al. (2000) Concurrent chemotherapy and pelvic radiation therapy compared with pelvic radiation therapy alone as adjuvant therapy after radical surgery in high-risk early-stage cancer of the cervix. J Clin Oncol 18: 1606-1613.

9. Rose PG, Bundy BN, Watkins EB, Thigpen JT, Deppe G, et al. (1999) Concurrent cisplatin-based radiotherapy and chemotherapy for locally advanced cervical cancer. N Engl J Med 340: 1144-1153.

10. Toita T, Kakinohana Y, Ogawa K, Adachi G, Moromizato H, et al. (2003) Combination external beam radiotherapy and high-dose-rate intracavitary brachytherapy for uterine cervical cancer: analysis of dose and fractionation schedule. Int J Radiat Oncol Biol Phys 56: 1344-1353.

11. Cetina L, Rivera L, Hinojosa J, Poitevin A, Uribe J, et al. (2006) Routine management of locally advanced cervical cancer with concurrent radiation and cisplatin. Five-year results. BMC Women's Health 6: 3

12. Punushapai $U$, Yuenyao $P$, Chumworathayi $B$, Luanratanakorn $S$ Udomthavornsuk B (2010) Weekly cisplatin $20 \mathrm{mg} / \mathrm{m} 2$ in patients with carcinoma of cervix receiving pelvic radiotherapy at Srinagarind Hospital: a randomized controlled trial. Asian Pac J Cancer Prev 11: 201-207.

13. http://www.ncrpindia.org/Reports/PBCR_2006_2008.aspx

14. Steel GG, Peckham MJ (1979) Exploitable mechanisms in combined radiotherapy-chemotherapy: the concept of additivity. Int J Radiat Oncol Biol Phys 5: 85-91.

15. DewitL(1987)Combined treatment of radiationand cisdiamminedichloroplatinum (II): a review of experimental and clinical data. Int J Radiat Oncol Biol Phys 13 $403-426$.
16. Richmond RC, Zimbrick JD, Hykes DL (1977) Radiation-induced DNA damage and lethality in $\mathrm{E}$. coli as modified by the antitumor agent cisdichlorodiammineplatinum (II). Radiat Res 71: 447-460.

17. Douple EB (1988) Platinum radiation interactions. NCI Monogr 6: 315-319.

18. Britten RA, Evans AJ, Allalunis-Turner MJ, Pearcey RG (1996) Effect of Cisplatin on the clinically relevant radiosensitivity of human cervical carcinoma cell lines. Int J Radiat Oncol Biol Phys 34: 367-374.

19. Chen AY, Okunieff P, Pommier Y, Mitchell JB (1997) Mammalian DNA topoisomerase I mediates the enhancement of radiation cytotoxicity by camptothecin derivatives. Cancer Res 57: 1529-1536.

20. Kuske RR, Perez CA, Grigsby PW, Lovett RD, Jacobs AJ, et al. (1989) Phase I/II study of definitive radiotherapy and chemotherapy (cisplatin and 5 -fluorouracil) for advanced or recurrent gynecologic malignancies. Preliminary report. Am J Clin Oncol 12: 467-473.

21. Stumpf J, Nemeth G, Takassi Wagu L, Naszali A (1989) Intra-arterial versus intravenous administration during intra cavitary irradiation of cervical tumors. Mould RE Brachytherapy Proceedings of Selectronuser's meeting 1988, The Hugue 324-7.

22. Vrdoljak E, Prskalo T, Omrcen T, Situm K, Boraska T, et al. (2005) Concomitant chemo brachy radiotherapy with ifosfamide and cisplatin followed by consolidation chemotherapy in locally advanced squamous cell carcinoma of the uterine cervix: Results of a phase II study. Int J Radiat Oncol Biol Phys 61 : 824-829.

23. Koumantakis E, Haralambakis Z, Koukourakis M, Mazonakis M, Haldeopoulos $D$, et al. (1998) A pilot study on concurrent platinum chemotherapy and intracavitary brachytherapy for locally advanced cancer of the uterine cervix. Br J Radiol 71: 552-557.

24. Strauss HG, Kuhnt T, Laban C, Puschmann D, Pigorsch S, et al. (2002) Chemoradiation in cervical cancer with cisplatin and high-dose rate brachytherapy combined with external beam radiotherapy. Results of a phaseII study. Strahlenther Onkol 178: 378-385. 